\title{
Durabilidad de los materiales naturales de construcción: percepciones de proyectistas, constructores y usuarios en Florianópolis, Brasil
}

\author{
Durability of natural building materials: Perceptions of designers, builders and users in Florianópolis, \\ Brazil \\ Durabilidade dos materiais naturais de construção: percepções de projetistas, construtores e \\ usuários em Florianópolis, Brasil
}

\section{Andrea Salomé Jaramillo-Benavides Zuleica Maria Patricio-Karnopp Lisiane Ilha-Librelotto \\ Universidad Federal de Santa Catarina (Brasil)}

Jaramillo-Benavides, A., Patricio-Karnopp, Z., \& Ilha-Librelotto, L. (2019). Durabilidad de los materiales naturales de construcción: Percepciones de proyectistas, constructores y usuarios en Florianópolis, Brasil. Revista de Arquitectura (Bogotá) 2/(2), 89-100. doi: http://dx.doi.org/10.147/8/ RevArq.2019.21.2.1825

\section{Andrea Salomé Jaramillo-Benavides}

Arquitecta, Pontificia Universidad Católica del Ecuador (Ecuador).

Maestría en Arquitectura y Urbanismo, Universidad Federal de Santa Catarina (Brasil).

Doctorado en Arquitectura y Urbanismo, Universidad de Santa Catarina (Brasil).

(D) https://orcid.org/0000-0002-2181-8042

andreasalome@gmail.com / andrea.jaramillo@ute.edu.ec

\section{Zuleica Maria Patricio-Karnopp}

Enfermera, Universidade Federal do Rio Grande do Sul (Brasil).

Especialista en Administración, Universidad do Sul de Santa Catarina (Brasil)

Maestría en Asistencia de Enfermería, Universidad Federal do Rio Grande do Sul (Brasil)

Doctorado en Salud-enfermería, Universidad Federal do Rio Grande do Sul (Brasil).

(D) https://orcid.org/0000-0002-7272-9816

zucamp@hotmail.com

Lisiane llha-Librelotto

Ingeniera civil, Universidad Federal de Santa Maria (Brasil).

Especialista en Gestión de Calidad, Universidad Federal de Santa Maria (Brasil).

Maestría en Ingeniería de Producción, Universidad Federal de Santa Catarina (Brasil).

Doctorado en Ingeniería de Producción, Universidad Federal de Santa Catarina (Brasil).

(D) https://orcid.org/0000-0002-3250-7813

lisiane.librelotto@ufsc.br

\section{Resumen}

A partir de una investigación de enfoque cualitativo, se buscó comprender la percepción de proyectistas, constructores y usuarios sobre la durabilidad de edificaciones construidas con materiales naturales. Participaron en el estudio profesionales y usuarios residentes en la ciudad de Florianópolis, Brasil. Se colectaron los datos por medio de entrevistas a profundidad y se analizaron con la técnica de análisis de contenido. Los resultados muestran el interés de las personas en un estilo de vida más sostenible, la relación de la durabilidad de esas construcciones con las necesidades de los usuarios, la calidad del proyecto arquitectónico y la dificultad para garantizarla por causa de las cadenas productivas poco desarrolladas y el desconocimiento de la población sobre técnicas adecuadas de construcción y mantenimiento. Este trabajo contribuye con enfoques sobre la sostenibilidad y la durabilidad de los materiales naturales, partiendo de experiencias de la práctica profesional, y señala algunas pautas para continuar las investigaciones en el área.

Palabras clave: análisis del ciclo de vida (ACV); arquitectura vernácula; bioconstrucción; desarrollo sostenible; permacultura; técnicas constructivas.

\section{Abstract}

This exploratory qualitative research sought to understand the perception of designers, builders, and users about the durability of buildings made with natural materials. The participants of this research were professionals and users from the city of Florianópolis, Brazil. The data was collected through in-depth interviews and analyzed using the content analysis technique. The results evidence an interest in a more sustainable lifestyle, the relationship between the durability of these constructions and user needs, the quality of the architectural project and the difficulty of guaranteeing quality by underdeveloped productive chains, as well as the inexperience of people regarding adequate construction techniques and maintenance. This paper offers approaches to understand the sustainability and durability of natural materials and presents professional practices as well as some guidelines to continue the research in this field.

Keywords: Life-cycle analysis (LCA); vernacular architecture; bioconstruction; sustainable development; permaculture; construction techniques tesis.

\section{Resumo}

A partir de uma pesquisa de abordagem qualitativa, pretende-se compreender a percepção de projetistas, construtores e usuários sobre a durabilidade de edificações construídas com materiais naturais. Participaram do estudo profissionais e usuários residentes da cidade de Florianópolis, Brasil. Os dados foram coletados por meio de entrevistas a profundidade e analisados com a técnica de análise de conteúdo. Os resultados mostram o interesse das pessoas em um estilo de vida mais sustentável, a relação da durabilidade dessas construções com as necessidades dos usuários, a qualidade do projeto arquitetônico e a dificuldade para garanti-la devido às cadeias produtivas pouco desenvolvidas e ao desconhecimento da população sobre técnicas adequadas de construção e manutenção. Este trabalho contribui com abordagens sobre a sustentabilidade e a durabilidade dos materiais naturais, partindo de experiências da prática profissional, e dá algumas instruções para continuar as pesquisas na área.

Palavras-chave: análise do ciclo de vida (ACV); arquitetura vernácula; bioconstrução; desenvolvimento sustentável; permacultura; técnicas construtivas.

\section{Introducción}

Este trabajo es parte de la fase exploratoria de la tesis de doctorado sobre la durabilidad del bambú en edificaciones de la región sur de Brasil, que está en desarrollo en el programa de posgrado en arquitectura y urbanismo de la Universidad Federal de Santa Catarina. Presenta una investigación de enfoque cualitativo llevada a cabo en la ciudad de Florianópolis, su objetivo es comprender la percepción de proyectistas, constructores y moradores sobre la durabilidad de las edificaciones construidas con materiales naturales.

Florianópolis es la capital del estado de Santa Catarina, en los últimos años registra un gran crecimiento poblacional. Según proyecciones del último censo del Instituto Brasileiro de Geografia e Estatística (IBGE, 2010), para 2017 la población de la ciudad fue de 485.838 habitantes. Muchas personas migran a esta urbe motivadas, entre otras razones, por la calidad de vida, las oportunidades de empleo, su singular geografía y atractivos naturales. La mayoría de estos últimos son playas y áreas de conservación ambiental que también atraen un número significativo de turistas cada verano, principalmente a la región insular. En la Figura 1 se muestran las áreas protegidas y urbanizadas, a fin de tener una idea de cómo la población de la ciudad está acostumbrada a vivir en un lugar que ofrece una gran proximidad con la naturaleza. 

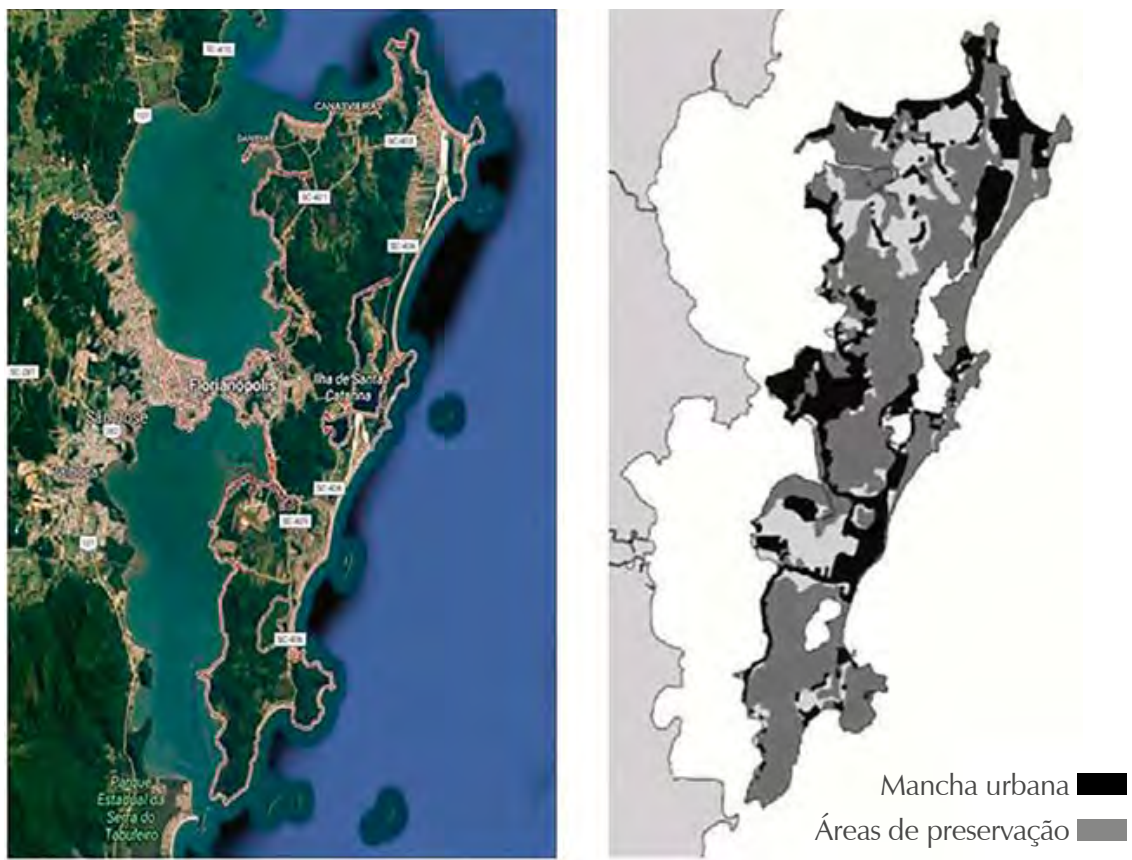

(A) Figura 1. Áreas de preservación ambiental y ocupación urbana en la isla - Florianópolis Fuente: Google maps (2017) (izq.) y Silveira y Rodrigues (2015) (der.)

\section{Materiales naturales y arquitectura sostenible}

En los albores de la humanidad los materiales naturales eran los únicos disponibles para la construcción: piedras, tierra, madera, paja, hojas de palmeras, bambú, entre otros, fueron trabajados y dispuestos de forma que pudieran ofrecer abrigo. Con el paso del tiempo, la tecnología y la técnica evolucionaron y surgieron nuevos materiales cuyas características los llevaron a una rápida inserción en el mercado y en la cotidianidad de las personas: concreto, acero, aluminio, plásticos, vidrio, entre otros, son usados y conocidos mundialmente por sus características de resistencia, durabilidad, altos niveles de industrialización, practicidad, acabado fino, facilidad de modulación y disponibilidad.

El auge del uso de estos materiales en la arquitectura se produjo en el siglo XX con el surgimiento del movimiento moderno, que instituyó un cambio en la relación de las personas con las construcciones y propició la aparición de nuevos requerimientos de desempeño de las edificaciones, adecuados a un estilo de vida marcado por la practicidad.

Con el paso del tiempo se ha observado que el consumo descontrolado de recursos naturales en la construcción tiene una gran repercusión en la crisis ambiental. Por este motivo, actualmente existe la necesidad de pensar en una arquitectura sostenible en los ámbitos social, económico y ambiental. Entre sus enunciados está la preferencia por insumos cuyo ciclo de vida represente un menor impacto al ambiente, es ahí donde se destacan los materiales naturales (Rocha-Tamayo, 2011).

Para este trabajo, los materiales naturales son definidos como aquellos de origen natural, que no hayan pasado por procesos de industrializa- ción o cuyo procesamiento haya sido realizado de modo artesanal o semiindustrial. Su disponibilidad y técnica de aplicación en las edificaciones varían dependiendo de la región geográfica y las condiciones del entorno.

En el ámbito social de la sostenibilidad de la construcción están incluidos los requerimientos de los usuarios, como lo indica la norma brasileña de desempeño de edificaciones NBR 15575 (Associação Brasileira de Normas Técnicas, 2013). En este sentido, el usuario es quien busca un grado de utilidad o aptitud de la edificación y sus elementos para satisfacer sus necesidades de confort o deleite, lo que en muchos casos es considerado como "valor arquitectónico".

El ser humano define este atributo partiendo de su historia, entorno y visión del mundo. Así, por un lado, la satisfacción de las necesidades al habitar un espacio podría ser establecida con base en las condiciones mínimas de habitabilidad y confort; pero por otro, está la sensación de bienestar y deleite que es más abstracta, por ejemplo, al apreciar una edificación como arte o símbolo.

Durante el siglo pasado, en la arquitectura racionalista primaba el valor funcional de una obra arquitectónica, abandonando estilos y valoraciones estéticas pasadas, para ponerla al servicio del ser humano (Randle, 2008, p. 40). El funcionalismo priorizó en la arquitectura valores inmediatos como: la facilidad de circulación, de mantenimiento, ventilación, iluminación, facilidad de montaje, etc., casi convirtiéndola en una tecnología de la construcción; en esta época modernista y de industrialización, las personas comenzaron a asociar lo bello a lo útil, sumando una valoración estética (inmaterial y subjetiva) a la técnica, "dos nociones que jamás podrán compensarse" (Ivelic, 1969, p. 43).

Walter Gropius (1962), desde su percepción racionalista y enfocada en las necesidades del ser humano, buscaba rescatar los valores estéticos y espirituales de la arquitectura; citando al zoólogo y naturalista Julian Huxley,

\footnotetext{
... más pronto que tarde nos veremos obligados a abandonar el sistema basado en el incremento artificial de los deseos del hombre y a construir uno orientado a satisfacer cualitativamente las necesidades humanas reales. Esto significa abandonar el hábito pernicioso de evaluar todo proyecto humano únicamente en términos de su utilidad (material o de ganancias para alguien). (1961, p. 25)
}

Sin embargo, algo que no fue citado por Gropius es que más adelante, en el mismo texto, Huxley continúa destacando la importancia de los valores espirituales para la realización personal, pero incluye a la naturaleza como parte de 
este proceso y al ser humano como un ser activo dentro de ella:

Los fines de la vida del hombre incluyen la creación y el disfrute de la belleza, natural y construida [...] la preservación de todas las fuentes de asombro y deleite como los paisajes, los animales en libertad o la naturaleza, el conseguir la paz y la armonía, la sensación de participar activamente en proyectos lógicos y perdurables, incluido el proyecto cósmico de la evolución. Es a través de estas cosas que los individuos alcanzan una mayor realización. (1961, p. 25)

Esta idea, que entonces fue disociada de la arquitectura, actualmente se ha convertido en un objetivo en algunos procesos de proyecto y construcción sostenibles. Un ejemplo de esto se observa en el contexto de la permacultura, "una cultura permanente y sostenible" (Holmgren, 2013, p. 3), donde la construcción es considerada uno de los ámbitos en los que se debe trabajar para conseguir este objetivo (Figura 2).
Dentro de los principios de la permacultura en el ámbito de la construcción están el uso de materiales naturales (como tierra, paja, cal, piedra, bambú) y la autoconstrucción de edificaciones, como una toma de poder de las personas sobre la construcción de sus hogares usando materiales y tecnología accesible (Holmgren, 2013).

La diversidad y complejidad de las diferentes sociedades y culturas traen consigo varias categorías de valoración de la arquitectura. Para Malard (2004, p. 2), en los últimos años en Occidente, con la evolución de las técnicas de representación, ha primado el valor visual de la arquitectura por encima de los demás. Este mismo autor caracteriza después las otras dimensiones de valoración con la siguiente afirmación: "el objeto arquitectónico es disfrutado en su dimensión artística, aprovechado en su dimensión utilitaria y construido en su dimensión tecnológica".

\section{La Flor de la Permacultura}

La trayectoria de la permacultura empieza con La Ética y los Principios de Diseño y se mueve a través de etapas claves necesarias para crear un futuro sostenible. Estas etapas están conectadas por un camino evolutivo en forma de espiral, inicialmente un nivel personal y local, para después proceder a lo colectivo y global.

A continuación se enumeran algunos de los campos específicos, sistemas de diseño y soluciones asociadas al uso generalizado de la permacultura:

Administración de la Tierra y de la Naturaleza

\begin{tabular}{ll}
\hline Huertos Biointensivos & Cultivo de secuencia natural \\
Bosques comestibles & Agroforestería \\
Conservación de semillas & Explotaciones forestales basadas en la \\
Agricultura Biológica & naturaleza \\
Agricultura Biodinámica & Acuicultura integral \\
Agricultura Natural & Caza y recolección \\
Cosecha de agua en línea clave & Recuperación de comida desechada \\
Manejo holístico de pastizales &
\end{tabular}
Manejo holístico de pastizales

\section{Construcción}

Diseño de energía solar pasiva Construcciones excavadas o uso Materiales de construcción naturales del suelo

Manejo del agua y reciclaje de desechos Construcción a prueba de desastres

Biotectura

naturales

Casas enterradas Lenguaje de patrones

Herramientas y Tecnología

Reutilización y reciclaje creativo

Herramientas manuales

Bicicletas normales y eléctricas

Cocinas de leña eficientes y poco

contaminantes

Combustibles de desechos orgánicos

Gasificación de madera

Biochar de desechos forestales

Cogeneración

Microturbinas hidroeléctricas y eólico a pequeña escala

Generación de energía renovable con conexión a la red

Almacenamiento de energía Ingeniería de transición

Educación y Cultura

\begin{tabular}{ll}
\hline Educación en casa & Ecología social \\
Educación Waldorf & Investigación activa
\end{tabular}

Cultura de la transición

Salud y Bienestar Espiritual

\begin{tabular}{ll}
\hline Parto natural y amamantar & $\begin{array}{l}\text { El espíritu del hogar, revivir las culturas } \\
\text { indígenas }\end{array}$
\end{tabular}
Medicina complementaria e integral Yoga, Tai Chi y otras disciplinas del cuerpo/mente/espíritu Morir con dignidad

Finanzas y Economía

\begin{tabular}{ll}
\hline Sistemas monetarios locales y & Inversiones éticas y comercio justo \\
regionales & WWOOFing (trabajo voluntario
\end{tabular}

regionales WWOOFing (trabajo voluntario en gran

Acuerdos para compartir vehículos orgánicas) y redes similares

Marcadillos de agricultores locales y Cuotas negociables de energía

agricultura sostenida por la comunidad Análisis del ciclo de vide y

(ASC) contabilización de la energía incorporada

Tenencia de la Tierra y Gobernación Comunitaria

Cooperativas y Corporaciones colectivas Título nativo y derecho de uso tradicional Tecnología del Espacio Abierto y toma de Compartir viviendas y Eco-aldeas decisiones por consenso

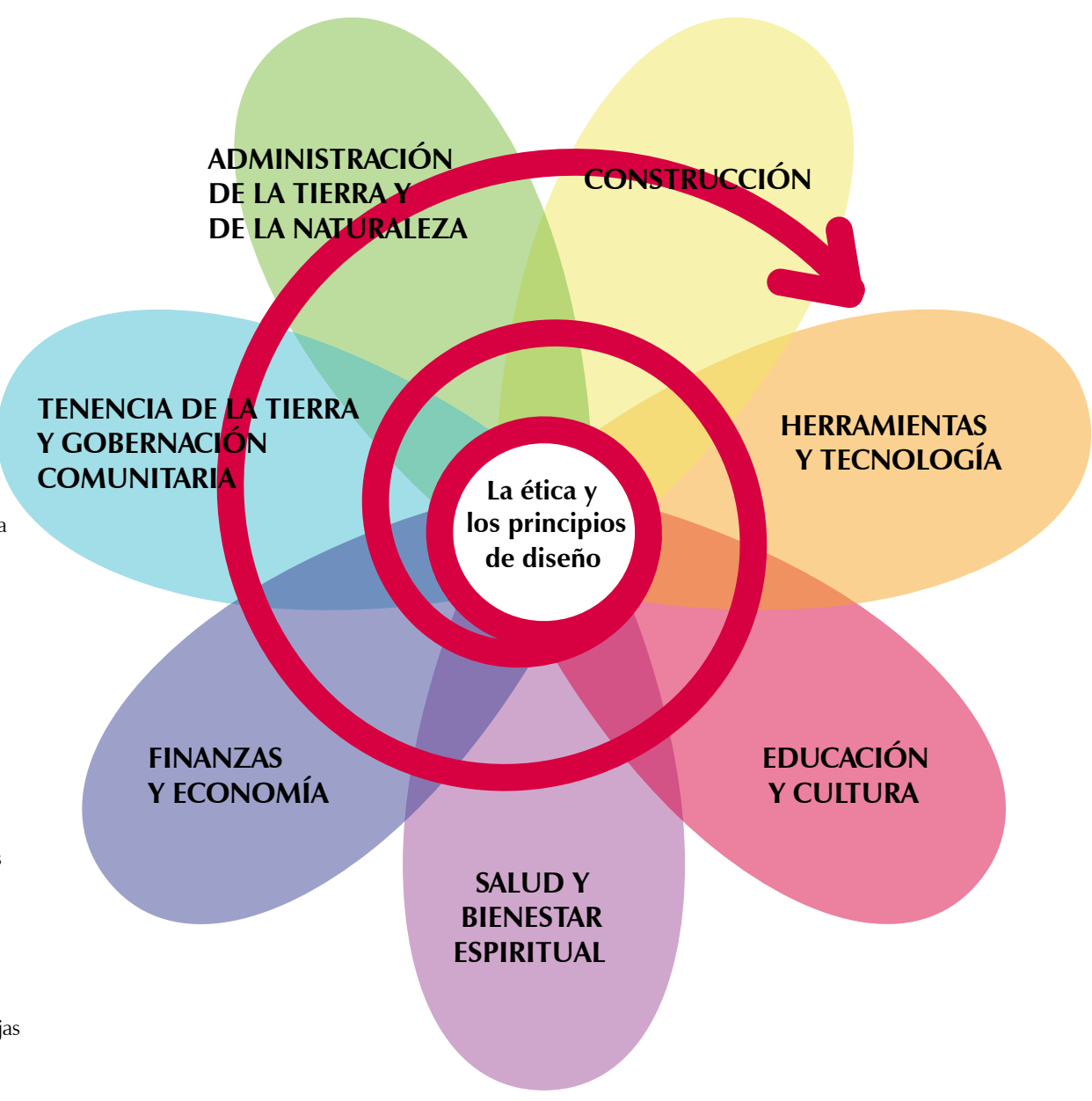


La elección de los materiales para un proyecto arquitectónico encajaría en la dimensión tecnológica. Pero en el caso de la preferencia por los materiales naturales, en esta época en que priman los industrializados (y sus ventajas), está relacionada también con una valoración previa de los usuarios, basada en aspectos más subjetivos y personales de su modo de habitar.

\section{Percepciones de los usuarios sobre la arquitectura}

Las personas construyen significados sobre los objetos con base en sus percepciones; la psicología ambiental ofrece herramientas para comprender ese proceso y los comportamientos relacionados con cada espacio en que los individuos desarrollan sus vidas (Kuhnen, 2011).

La palabra percepción proviene del latín perceptio, que es la acción y el efecto de percibir-recibir por medio de los sentidos. Cada individuo posee una percepción única de las cosas y los fenómenos que lo rodean, de esto dependerá su entendimiento del mundo, sus comportamientos y elecciones:

\section{La percepción humana se construye a partir de un compromiso ético, activo con el mundo, y no como una contemplación [...]. En esta perspec- tiva, se encuentran los individuos activos, cons- tructores de sentidos, de realidades, que perciben el espacio y crean imágenes y sistemas de acción [...]. Percibir requiere también actuar en el mundo y, a partir de esa actuación, las personas van cons- truyendo su subjetividad. (Kuhnen, 2011, p. 253)}

Una mayor comprensión de las percepciones de las personas sobre los espacios sirve para entender sus apreciaciones y comportamientos en relación con ellos. Gifford (2007) indicó que las acciones que cada individuo desarrolla en el ambiente lo transforman y generan un ciclo de acción y reacción.

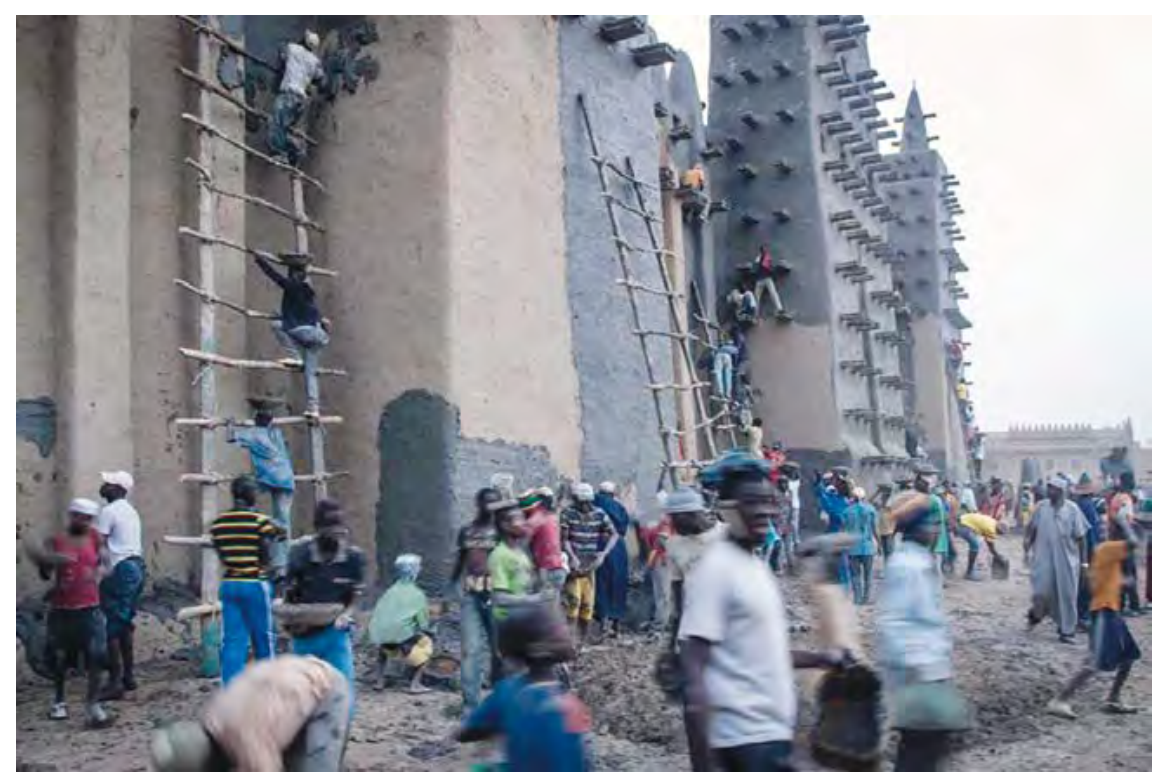

En la construcción de la percepción ambiental de cada individuo, imágenes o representaciones de la realidad se elaboran en un proceso de internalización de experiencias cotidianas, de las sensaciones que ellas producen y su relación con los recuerdos de su vida (Kuhnen, 2011). Cada ambiente es un reflejo de los aspectos socioculturales de las personas involucradas en el proceso de proyectar, construir y habitar ese espacio.

\section{Durabilidad de los materiales de construcción - Percepciones}

Un aspecto importante en el proceso de diseño y construcción con materiales naturales es la durabilidad. Existe una preocupación generalizada en relación con el tema, que en algunos casos emerge como miedo o prejuicio, como será mostrado más adelante.

La norma brasileña NBR 15575 (ABNT, 2013) define la durabilidad como "la capacidad de una edificación o de sus sistemas para desempeñar satisfactoriamente sus funciones a lo largo del tiempo, bajo condiciones de uso y mantenimiento especificadas", lo que la relaciona directamente con la funcionalidad y, por tanto, con un estilo de vida.

John y Sato (2006, p. 24) afirman: "la durabilidad no es una propiedad inherente de un material o componente, sino el resultado de la interacción del material y el medio ambiente que lo rodea, incluyendo aspectos de microclima". Esto se relaciona con la arquitectura, que considera las necesidades de los usuarios y las características del entorno.

Si por un lado el hecho de comprender las necesidades, percepciones y sensaciones de los usuarios en determinados espacios ayuda a entender mejor cómo esos ambientes -y sus materiales, colores, texturas, iluminación- influyen en el comportamiento de estas personas (Scopel, 2015); por otro, las decisiones de los usuarios y diseñadores sobre los espacios muestran sus percepciones de habitar, lo que quieren transmitir y vivenciar.

¿Y si para ellos la edificación fuera considerada un objeto con determinado valor histórico-social que está en continua construcción y modificación, donde el esfuerzo invertido en su mantenimiento no sería un desperdicio, sino un modo de relación con el edificio? La poca durabilidad de los materiales de esa construcción no sería realmente vista como un problema sino simplemente una característica, algo que debe ser considerado dentro de su rutina de vida.

Ese es el caso de la mezquita de Djenné (Figura 3), construida en Malí en el siglo XII, que fue destruida y restaurada en el siglo XIX. Actualmente es el edificio de adobe más grande del 
mundo, con más de $5000 \mathrm{~m}^{2}$. Cada año, durante el festival de primavera crepissage, bajo la dirección de 80 albañiles expertos, la comunidad participa de una minga para enlucir la edificación (May, 2011).

Aunque este es un caso puntual de un edificio público, sirve para entender que podrían existir otras formas de relación, otros puntos de vista sobre los espacios y la durabilidad de los materiales de construcción, otros requisitos y prioridades que los usuarios pueden tener sobre los lugares que habitan.

Siguiendo este razonamiento, si existen personas que proyectan o buscan habitar en edificaciones hechas con insumos naturales en las ciudades, probablemente ya investigaron sobre las características de estos materiales, tienen un criterio diferente sobre el tema o consiguieron explicar (y resolver) el "problema" de la durabilidad de algún modo.

Lo que los proyectistas y usuarios de las edificaciones construidas con materiales naturales perciben sobre este tema puede aportar al entendimiento de estilos de vida contemporáneos, con otras valoraciones y formas de relación con las construcciones, otros modos de habitar $y$, finalmente, aclarar nuevos caminos hacia una arquitectura sostenible.

\section{Metodología}

Esta investigación tiene un enfoque cualitativo, con el propósito de comprender la percepción de proyectistas, constructores y moradores sobre la durabilidad de edificaciones de materiales naturales en la ciudad de Florianópolis, Brasil.

Las investigaciones cualitativas son adecuadas para indagar situaciones sociales y entender las subjetividades de las expresiones humanas, así como las simbologías con las que el ser humano convive. Su propósito es la comprensión de un fenómeno y no la cuantificación o generalización de los resultados; Minayo (2014, p. 57) indica que "se caracterizan por el empirismo y la sistematización progresiva del conocimiento hasta la comprensión de la lógica interna del grupo o proceso estudiado".

En este sentido, Karnopp-Patricio, Moraes, Campanella y Nakadomari (2016) presentan una analogía entre el cotidiano de la arquitectura y el urbanismo con las investigaciones cualitativas, explicando que ninguna pretende comprobar hipótesis, al contrario, sus resultados presentan una o varias suposiciones sobre un determinado fenómeno, lo que origina más interrogantes. En ambos casos no existe una única solución correcta para cada situación o problema, sino varias posibilidades.
La arquitectura y el urbanismo buscan respuestas a necesidades humanas dentro de la complejidad de las relaciones sociales y espaciales. Karnopp-Patricio et al. (2016) explican que la investigación cualitativa es utilizada por profesionales de estas áreas para elaborar, dar seguimiento y evaluar sus proyectos; porque sus herramientas facilitan la comprensión de fenómenos humanos en un determinado contexto (físico, histórico, sociocultural, político, espiritual, económico, etc.) y permiten desarrollar habilidades de investigación e interacción con otras personas en varias situaciones.

Siguiendo los lineamientos del enfoque cualitativo, el levantamiento de datos se realizó en el mismo ambiente donde el fenómeno social se desarrolla, en este caso, la ciudad de Florianópolis. El texto de Karnopp-Patrício (2005) orientó la ejecución de la investigación durante las etapas de entrada, permanencia y salida de campo.

Para la colecta de datos fueron utilizadas las técnicas de entrevista semiestructurada y observación participante con apoyo de un formulario propio, adaptado del modelo de Karnopp-Patricio (1995); este documento estaba compuesto por cinco ítems que siguen el rigor metodológico de la investigación cualitativa, incluyendo sus principios éticos: identificación del proyecto de investigación, caracterización de los participantes y de las categorías de análisis, un espacio para la expresión libre del entrevistado sobre el tema, finalización de la entrevista y las notas del investigador. Las preguntas se aplicaron sin un orden específico con el objetivo de no influir en las respuestas, solamente fueron utilizadas como guía de los temas que debían abordarse y observarse; estas fueron:

1. ¿Por qué escogió trabajar principalmente con materiales naturales?

1.1 ¿Cuáles son las limitantes de trabajar con materiales naturales?

1.2 ¿Cuáles son sus referentes arquitectónicos/constructivos para trabajar con estos materiales?

2. ¿Qué percibe en el medio donde vive en relación con las edificaciones construidas con materiales naturales?

2.1 ¿Por qué las personas (sus clientes) buscan proyectos construidos con materiales naturales?

2.2 ¿Cómo es la relación de los usuarios con una construcción de materiales naturales comparada con una de materiales convencionales?

3. ¿Cuál es su opinión sobre la durabilidad de las edificaciones y de los materiales de construcción? 
3.1 ¿Cuál sería la durabilidad ideal de una vivienda construida con materiales naturales?

3.2 Comparta alguna experiencia relacionada con este tema.

4. ¿Cuál es su opinión sobre la relación arquitectura-sustentabilidad?

Para este estudio fueron entrevistados siete profesionales en proyecto y construcción de edificaciones con materiales naturales en Florianópolis: cinco arquitectos, un ingeniero civil y un artesano; cuatro de ellos viven en casas hechas con esos materiales. La selección de estos participantes también siguió el enfoque cualitativo, donde la cantidad de la muestra no es un criterio importante comparado con la profundidad del asunto investigado.

De esta manera, la cantidad y el perfil de los entrevistados en este estudio fueron definidos por los siguientes criterios: a) el profesional debe realizar, principalmente, trabajos de proyecto o construcción con materiales naturales, b) tener por lo menos tres años de experiencia en el área, c) trabajar principalmente en Florianópolis, d) ser reconocido en el área de la construcción de este tipo de edificaciones en esta ciudad, e) estar dispuesto a participar de la investigación.

Previo a las entrevistas, cada uno de los profesionales firmó un consentimiento libre y esclare- cido de su participación, donde se especificaba información sobre la investigación, tal como los objetivos y el método, su autorización para grabar las entrevistas y la forma en que sería utilizada la información levantada. Se garantizaron los principios éticos de anonimato y confidencialidad de acuerdo con lo indicado por la Comisión Nacional de Ética en Pesquisa de Brasil (Conep, 2018).

Después de transcribir las entrevistas grabadas, fueron registradas las percepciones de la investigadora en los formularios correspondientes, de acuerdo con las orientaciones metodológicas.

El análisis de los datos se desarrolló con la técnica de análisis de contenido, siguiendo las orientaciones de Bardin (1991) y Minayo (2014), lo que resultó en categorías -conceptos clasificatorios-, sin la intención de cuantificación. Estas fueron definidas a partir de las preguntas semiestructuradas utilizadas en la fase de levantamiento de datos y después del proceso de análisis-reflexión-síntesis que posibilitó identificar temas emergentes; así fue posible establecer el conjunto de cuatro categorías (tabla 1) que orientaron el análisis de los resultados.

De esta manera, se usó el análisis temático, indicado por Minayo (2014, p. 316) como una modalidad de análisis de contenidos que consiste en "descubrir los núcleos de sentido que componen una comunicación, cuya presencia o frecuencia signifiquen algo para el objeto analítico".

\section{Categorías}

Acontecimientos, registros cercanos

\section{Tópicos/entrevista}

Situaciones/casos relacionados con los usuarios de viviendas hechas con materiales naturales y durabilidad

Lo que han visto sobre lo que las personas piensan sobre este tipo de construcciones

Perfil de las personas que buscan proyectos con materiales naturales

Motivos de desistimiento de los clientes del uso de materiales naturales

Dificultades/problemas de trabajar con esos materiales en el área de la construcción $\otimes$ Tabla 1. Categorías de análisis y tópicos de las entrevistas

Fuente: elaboración propia, 2017.

$\begin{gathered}\text { Dificultades/problemas de trabajar con esos materiales } \\ \text { en el área de la construcción }\end{gathered}$
Ideas propias sobre durabilidad de materiales y edificaciones
Mundo físico
Sensaciones/pensamientos sobre habitar una casa construida
con materiales naturales




\section{Resultados y discusión}

\section{Percepciones de los participantes}

Solo uno de los participantes nació en Florianópolis, pero todos ellos viven o trabajan principalmente en esta ciudad. Esta sección presenta sus percepciones en relación con las cuatro categorías de análisis.

\section{Sobre los registros cercanos}

Lo que la gente piensa y siente en relación con las construcciones con materiales naturales depende de sus experiencias personales. En este estudio, por medio de las percepciones de los entrevistados, basadas en su experiencia de trabajo, se identificaron tres grupos principales: las personas que tienen percepciones negativas $y$ no buscan este tipo de construcciones, las que tienen percepciones positivas pero acaban desistiendo de la construcción durante el proceso por varios motivos, y las que tienen una percepción positiva y construyen con estos materiales.

El primer grupo siente inseguridad en el uso de estos materiales y no tiene conocimientos de las técnicas, por ejemplo, a veces piensa que las construcciones de tierra "se van a deshacer" con el tiempo o que no funcionan en el clima de la ciudad. Un caso relatado por uno de los entrevistados fue que en el interior del estado algunas personas, al ver su propuesta, dijeron que una construcción de tierra podría "derretirse", y hasta hubo peleas familiares por la no aceptación del material. En este sentido, dos ideas principales fueron resaltadas por los entrevistados:

- Muchas veces los usuarios rechazan estos materiales por haber visto casos de mala aplicación y por la idea de altos costos de mantenimiento.

- Hay personas que piensan que trabajar con materiales naturales "es retrógrado, como si fuera algo anticuado que rechaza los materiales y el conocimiento actuales, un tipo de negación del futuro".

Por otro lado, están los clientes que los entrevistados tuvieron con más frecuencia: aquellos que quieren tener una conexión con la naturaleza y la sostenibilidad, que les gusta la apariencia del material natural o quieren hacer algo diferente. Generalmente llegan con alguna información recolectada pero preocupados con la confiabilidad del resultado de la construcción, siempre existe una comparación con el concreto. Hay casos en que superan su inquietud al entender las características de los materiales y su confianza crece a medida que avanzan el proyecto y la construcción, otros desisten de su uso.
En los casos en que los clientes desistieron de construir con estos materiales se identificaron varios motivos: preocupación con el mantenimiento o con la durabilidad, falta de garantías técnicas y tiempo de ejecución. De este modo, se identifica que la inseguridad de las personas sobre el uso de materiales naturales nace del desconocimiento de sus propiedades y de las técnicas adecuadas de aplicación. Esto se relaciona directamente con la dimensión tecnológica de la arquitectura, mencionada por Malard (2004), que sería el motivo principal de desvalorización de estas edificaciones para los usuarios.

Además, la dimensión tecnológica de este tipo de construcciones aparece también como un obstáculo en el ejercicio profesional de los entrevistados, al ver los problemas que enfrentan diariamente:

- Falta de mano de obra calificada. Ellos la están formando continuamente y debe ser especializada para cada material.

- No hay proveedores de materia prima lista. En algunos casos, como el bambú, los proyectistas deben "ser" toda la cadena productiva, trabajando en la colecta, el tratamiento, el secado y la aplicación para poder garantizar un producto final de calidad. Esto interfiere en el tiempo de construcción de la obra.

- Desconocimiento generalizado de estos materiales. Los proyectistas deben enseñar, convencer y probar que las técnicas funcionan.

- Ausencia de normas técnicas en el país para los casos de construcciones con tierra y bambú.

- La idea de que construir con materiales naturales es más barato, lo que no siempre es verdad si la calidad es considerada, todo depende del proyecto.

- Falta más investigación e inclusión del tema en los cursos universitarios.

Por otro lado, las motivaciones de los usuarios para vivir en edificaciones construidas con materiales naturales están relacionadas con la estética y la valoración ambiental: en algunos casos ellos comienzan a construir con materiales naturales deslumbrados con la cuestión ecológica y los acabados, sin profundizar en detalles más específicos relacionados con la preparación y el uso adecuado de los materiales; se aventuran sin mucho conocimiento $y$, en la mayoría de los casos, sus experiencias no son exitosas, entonces acaban por culpar al material.

En este sentido, es necesario destacar que las personas que tienen una percepción positiva y experiencias exitosas con materiales naturales en la construcción, sienten seguridad y deleite en todas las dimensiones de la edificación: artística (o estética), utilitaria, ambiental y tecnológica. Este es el 
caso de los clientes que confiaron en la solución que el profesional entrevistado ofreció y se sienten bien en una casa con materiales naturales.

Fueron citados varios casos de clientes con experiencias satisfactorias, que se sienten saludables y realizados. Uno de ellos fue una persona que siente su casa más ecológica y sostenible, lo que lo incentivó a llevar esta idea también a su jardín y otros sistemas, como el de colecta de agua de lluvia.

Aun así, en algunas ocasiones, las casas están ya habitadas y los usuarios se alarman cuando aparece una patología menor, comienzan a dudar de los materiales y llaman a los profesionales para verificar que todo esté bien.

\section{Sobre el mundo físico}

Fue casi unánime entre los entrevistados la afirmación de que la durabilidad de las edificaciones depende de varios factores: el conocimiento de una técnica adecuada, la disponibilidad de mano de obra, el conocimiento sobre el material y el contexto de la edificación. Fueron mencionados casos de construcciones de muchos años hechas con esos materiales, y se relataron experiencias propias o de conocidos para demostrar la durabilidad de los materiales naturales.

La durabilidad también fue relacionada con la posibilidad de adaptación de los materiales durante los mantenimientos, lo que prolonga la vida útil de la edificación; al respecto, uno de los entrevistados mencionó: "hay estudios que muestran que el sistema constructivo de woodframe [Figura 4] tiene mayor vida útil que el de concreto o el acero en Norteamérica, porque posibilita la manipulación y adaptación a nuevos usos". Esto en referencia a la investigación de North American Forest Products Industry by the BC (BSLC, 2009)

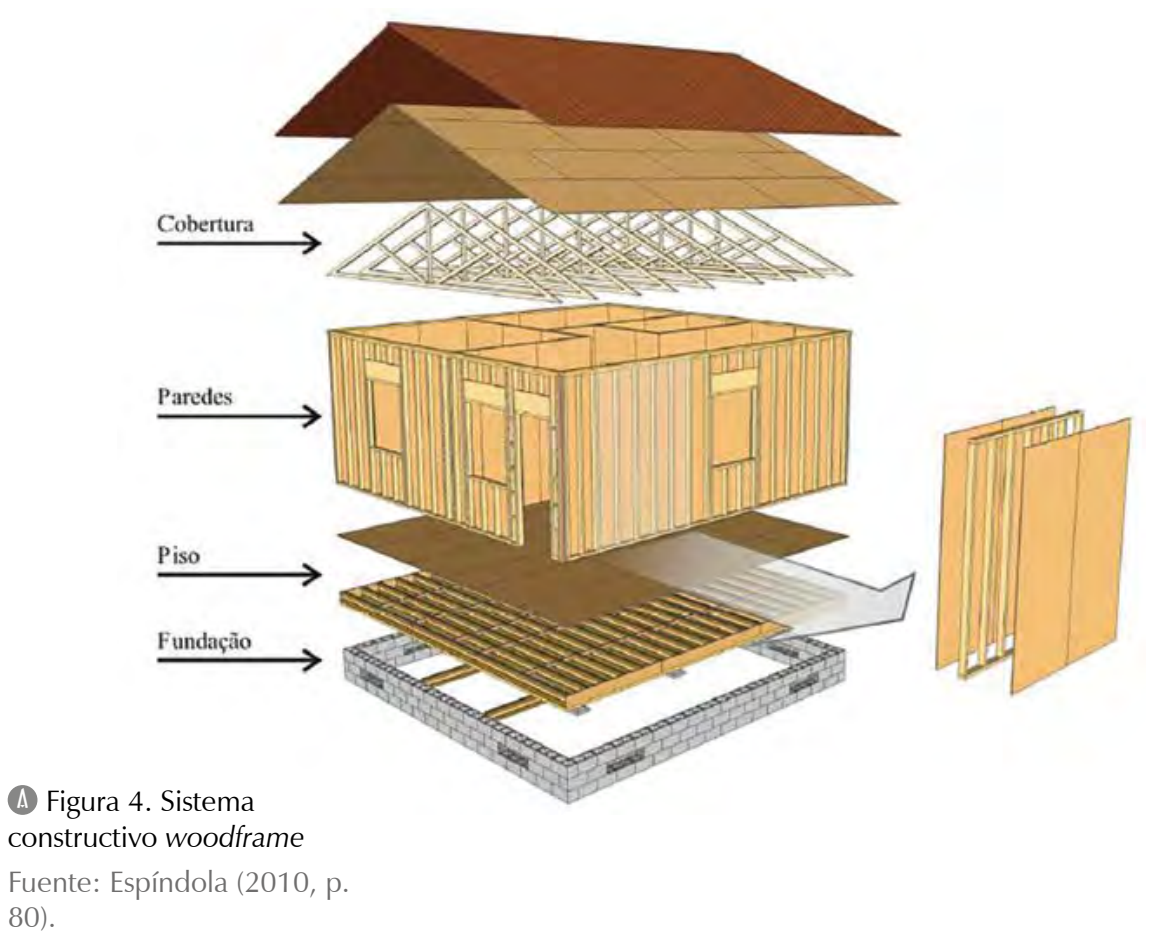

en Mineápolis, que indica una mayor expectativa de vida útil para las edificaciones de madera, considerando su posibilidad de adaptación espacial y funcional, lo que está directamente relacionado con el proyecto y la técnica constructiva.

La confianza de los entrevistados en la durabilidad de los materiales naturales en la construcción viene del ejercicio profesional y la investigación. Está basada en probar los materiales antes de su aplicación por medio de experimentos prácticos y también en testimonios propios de vivir en este tipo de casas por más de diez años.

Un entrevistado indicó que al inicio de su vida profesional, motivado por las prácticas en permacultura, pensó en usar únicamente materiales naturales, como maderas sin tratamiento; pero su deterioro en algunas áreas de la edificación le mostró limitaciones en la aplicación. Con base en este tipo de experiencias las visiones muy "activistas" cambian para un pensamiento menos radical y aparece la necesidad de aliar materiales naturales con los industrializados para obtener una mayor eficiencia.

Sobre la pregunta por la durabilidad ideal de una casa construida con materiales naturales, casi todas las respuestas coincidieron en que está definida por las necesidades del cliente. Pero el profesional de ingeniería civil se mostró más cauteloso e indicó que diez años es un buen periodo de prueba, comentó que tuvo la oportunidad de participar de varias construcciones de este tipo hace más o menos diez años y están "todavía en pie" $^{\prime \prime}$.

Este es un punto crítico, considerando principalmente que la norma de desempeño de edificaciones NBR 15575 (Associação Brasileira de Normas Técnicas, 2013) establece un tiempo mínimo de vida útil de cincuenta años para las edificaciones. Sin embargo, la falta de estudios y otros documentos técnicos que garanticen la vida útil de materiales naturales en edificaciones, con excepción de la madera, es una vez más una limitante en el ejercicio profesional de los entrevistados.

En relación con la sostenibilidad de los materiales naturales, esta fue abordada desde varios puntos de vista. Inicialmente, todos mencionaron que estos materiales están asociados a un estilo de vida más cercano a la naturaleza (Figura 5), a la búsqueda de recursos naturales para construir y al menor impacto ambiental. Posteriormente abordaron otros temas relacionados con la parte económica y social.

En este contexto se mencionó que "el proceso de construcción con tierra es más humanizado y no tan agresivo con los trabajadores como otras técnicas, porque la tierra es un material local que puede aplicarse en mingas, por ejemplo". Esta afirmación remite a uno de los principios de la 


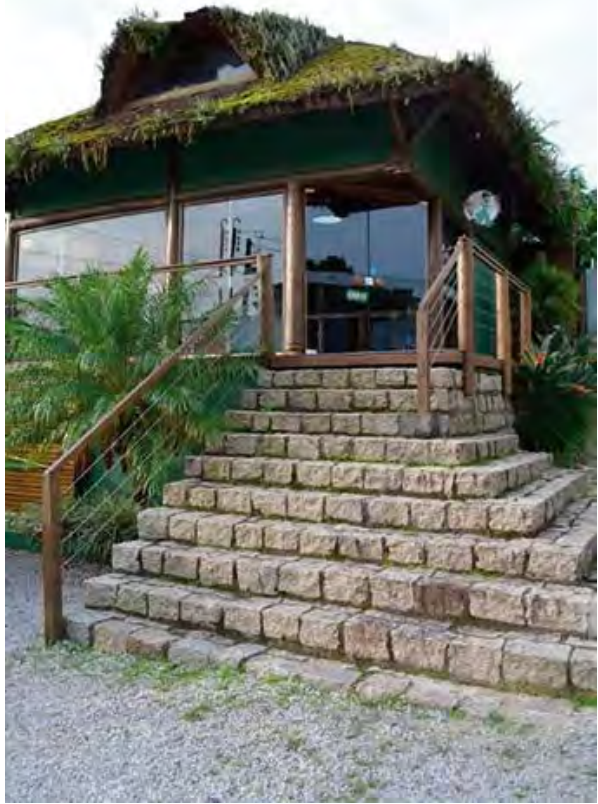

(A) Figura 5. Materiales naturales en una edificación en Florianópolis

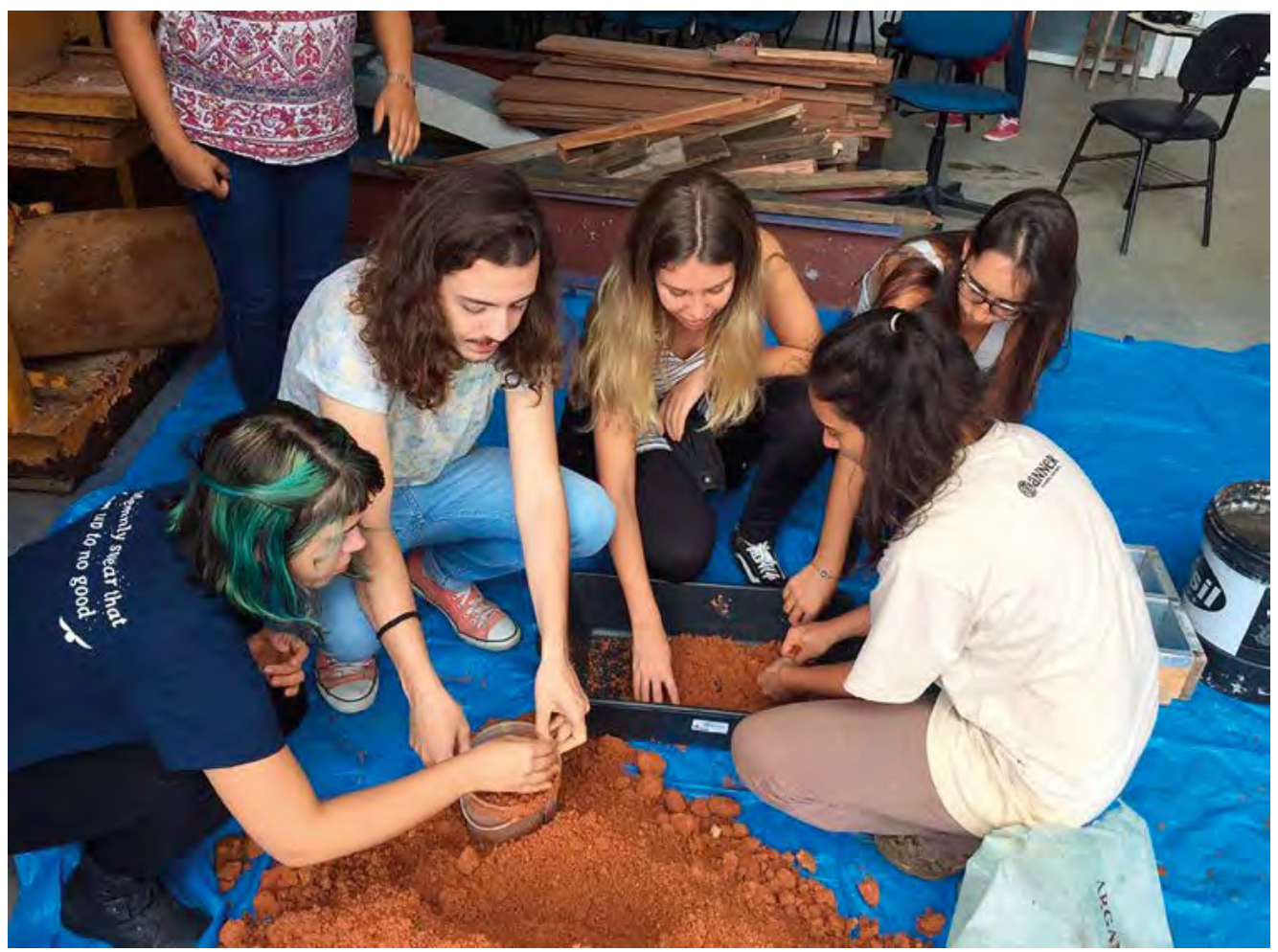

Fuente: elaboración propia, 2017

construcción en la permacultura: autoconstrucción para dar autonomía y empoderar económicamente a los usuarios o las comunidades, usando tecnologías y materiales accesibles (Holmgren, 2013).

Es así que por un lado se tiene la valoración ambiental del material y la técnica, por otro aparece con fuerza el factor social, que incluye una relación directa - sin perjuicios para la saludde las personas con el material y la posibilidad de que la construcción con este genere otros procesos de relación entre miembros de una comunidad.

En la Figura 6 se observa la elaboración manual de adobes. Uno de los entrevistados contó su experiencia con este material de construcción como una alternativa para personas de escasos recursos económicos que tienen un terreno, pues consiguen construir su casa con asesoría técnica y aprenden el proceso, lo que puede representar nuevas posibilidades de trabajo.

Antiguamente, las personas construían con lo que tenían disponible, cada lugar y cada material tienen características que deben ser entendidas para conseguir la armonía necesaria para una buena técnica de ejecución, "es necesario respetar el local, el material disponible y el ambiente". Estas afirmaciones de los entrevistados destacan la importancia de retomar conocimientos ancestrales de construcción, adquiridos durante siglos de uso de materiales naturales; en este sentido existen algunas investigaciones como las de Morán (2001), Hidalgo-López (2003) y Minke (2012), que extraen aprendizajes de técnicas constructivas vernáculas para presentar opciones de aplicación en la actualidad, que en muchos casos aún deben ser estudiadas a profundidad en varios aspectos puntuales relacionados con el desempeño en diferentes contextos.

Otro punto que los entrevistados mencionaron dentro del tema de la sostenibilidad es la necesidad de pensar en el proceso de extracción y transformación de los materiales antes de su aplicación, fundamental para evaluar su impacto ambiental; porque "la industria vende un material que se dice natural, pero desconocemos su procedencia y composición".

Frente a esto, el análisis del ciclo de vida (ACV) de los materiales es una herramienta que cuantifica y evalúa los impactos de las diversas fases del proceso constructivo en el ambiente -incluida la fase de extracción o fabricación de los materiales-, por este motivo puede ayudar a la toma de decisiones de proyecto y construcción (Soares, Souza y Pereira, 2006, p. 104).

El uso de este tipo de herramientas es necesario al momento de determinar el grado de sustentabilidad de un material porque no todos los materiales industrializados son totalmente nocivos para el ambiente, como tampoco el uso de materiales naturales garantiza un bajo impacto ambiental. Un ejemplo de esto fue dado por uno de los entrevistados, en referencia al manejo sostenible del bambú: una persona arrasó completamente una macolla para construir una edificación, sin pensar en la calidad del material ni en la conservación de la planta para uso futuro. Junto con el uso del material es necesario desarrollar una cadena productiva que garantice la sostenibilidad económica y ambiental de los procesos.

Finalmente, dentro de la valoración espiritual de las edificaciones, los entrevistados que viven
(A) Figura 6. Elaboración de adobes para pruebas de proporciones

Fuente: elaboración propia, 2017. 
T) Tabla 2. Experiencia de trabajo (en años) y motivaciones de los profesionales

Fuente: elaboración propia, 2017. -o ya vivieron- en casas construidas con materiales naturales expresaron sus sensaciones o ideas sobre habitar estos espacios:

Yo tengo cariño por las cosas de la casa, pienso que son elementos más vivos. En la práctica no siento cambios.

La diferencia es solo psicológica, es el mismo confort, depende mucho del proyecto. Sentirse más cerca de lo natural y de un padrón o concepto de sostenibilidad.

Viví en una casa de madera y fue una buena experiencia, tenía una poética y un buen desempeño térmico en su contexto.

Si yo fuera un novato vería solo bambú, pero yo hice la casa, sé todos los detalles y la técnica [...] recuerdo la parte constructiva [...] yo hice mi propia casa hace 11 años y el bambú está firme y fuerte. En Brasil poca gente tiene la oportunidad de vivir en una casa de bambú.

En los dos primeros casos las casas fueron principalmente construidas con tierra, la última tiene varios materiales, pero el participante prefirió enfocarse en el bambú. Las diferencias identificadas se relacionan con el afecto por al lugar y evocaciones de experiencias personales con los materiales.

\section{Sobre experiencias y motivaciones}

La motivación común identificada entre los entrevistados para trabajar con estos materiales fue la preocupación por la naturaleza, con algunas variantes dependiendo del estilo de vida de cada participante. Todos ellos se mostraron optimistas en relación con su trabajo en esta área y mencionaron planes futuros. En la Tabla 2 se muestra el tiempo de trabajo de cada profesional y sus motivaciones principales.

Sobre las acciones de educación continua y multiplicación de saberes

Todos los profesionales investigan por su cuenta los materiales naturales, algunos están cursando posgrado para profundizar y hacer alguna contribución en el área. La mayor parte de sus conocimientos vinieron de cursos sobre bioconstrucción, permacultura, conferencias, viajes, lecturas y contacto con otros expertos nacionales y extranjeros. Conocer la existencia de obras y proyectos con estos materiales en otros lugares del mundo es una de sus motivaciones.

Frente a la falta de educación formal en este tema, seis de los profesionales dictan talleres sobre construcción con materiales naturales para todo público, el séptimo da clases en la carrera de Arquitectura de una universidad, en materias cuyo enfoque no son los materiales.

Existe una demanda para aprender técnicas de construcción con estos materiales. Soares (2015) revela que más de 10.000 personas asistieron a cursos de construcción con materiales naturales en Brasil, estos espacios también facilitan el intercambio de experiencias sobre la mejora de las técnicas constructivas y la solución de problemas que los profesionales de esta área enfrentan diariamente.

En relación con lo que hacen frente a las dificultades que surgen en su trabajo, los entrevistados indicaron: (incluso personal) sobre el ambiente. Ahora cree en el compromiso de los arquitectos con un entorno más natural. 
- Diálogo con los clientes. Educación y socialización sobre el uso de materiales y sus características, con ejemplos simples como "existe la misma posibilidad de una madera ser infestada por termitas como de un acero oxidarse", la diferencia está en la aplicación.

- Trabajo con los materiales desde la extracción hasta la aplicación para garantizar su calidad.

- Valorar la mano de obra, tanto en la formación como en la remuneración, para tener una mejor calidad técnica. "Es una recuperación del trabajo humano sobre las máquinas, una visión más humana".

- Difundir sus servicios en lugares con público específico, como aquellos de atmósfera más holística y espiritual. Por ejemplo, la Aldea Índigo, ubicada en el barrio de Campeche, que ofrece actividades de yoga, meditación, terapias, restaurante vegano y tiene su espacio construido con materiales naturales (Figura 7).

- Participan en comités técnicos para la aprobación de normas con estos materiales.

- Actualizan continuamente sus conocimientos.

\section{Conclusiones}

El uso de materiales naturales en la construcción está relacionado con un estilo de vida más sostenible. Esta es la motivación principal de los usuarios y los profesionales que deciden trabajar en esta área.

En este estudio se evidenció que, si bien muchas veces la parte estética y ambiental de una construcción con materiales naturales es atractiva para los usuarios, la incertidumbre sobre la durabilidad, entre otros asuntos relacionados con la parte tecnológica y de desempeño, es determinante para que desistan de usar esta opción en sus proyectos. Esta inseguridad está basada en experiencias personales de mala aplicación o falta de mantenimiento del material, y la ausencia de respaldos técnicos como normas de construcción en el país.

Por otro lado, los profesionales entrevistados reconocen la durabilidad como un punto crítico, pero parten de un punto de vista técnico que les permite entender y enfrentar el "problema" relacionando los materiales con las demandas de los clientes y adecuando el proyecto al entorno. Sin embargo, tampoco encuentran los respaldos suficientes para ofrecer, de forma contundente, garantías en sus propuestas.

Los materiales naturales más utilizados por estos profesionales en Florianópolis son la madera, el bambú y la tierra. La formación sobre téc-

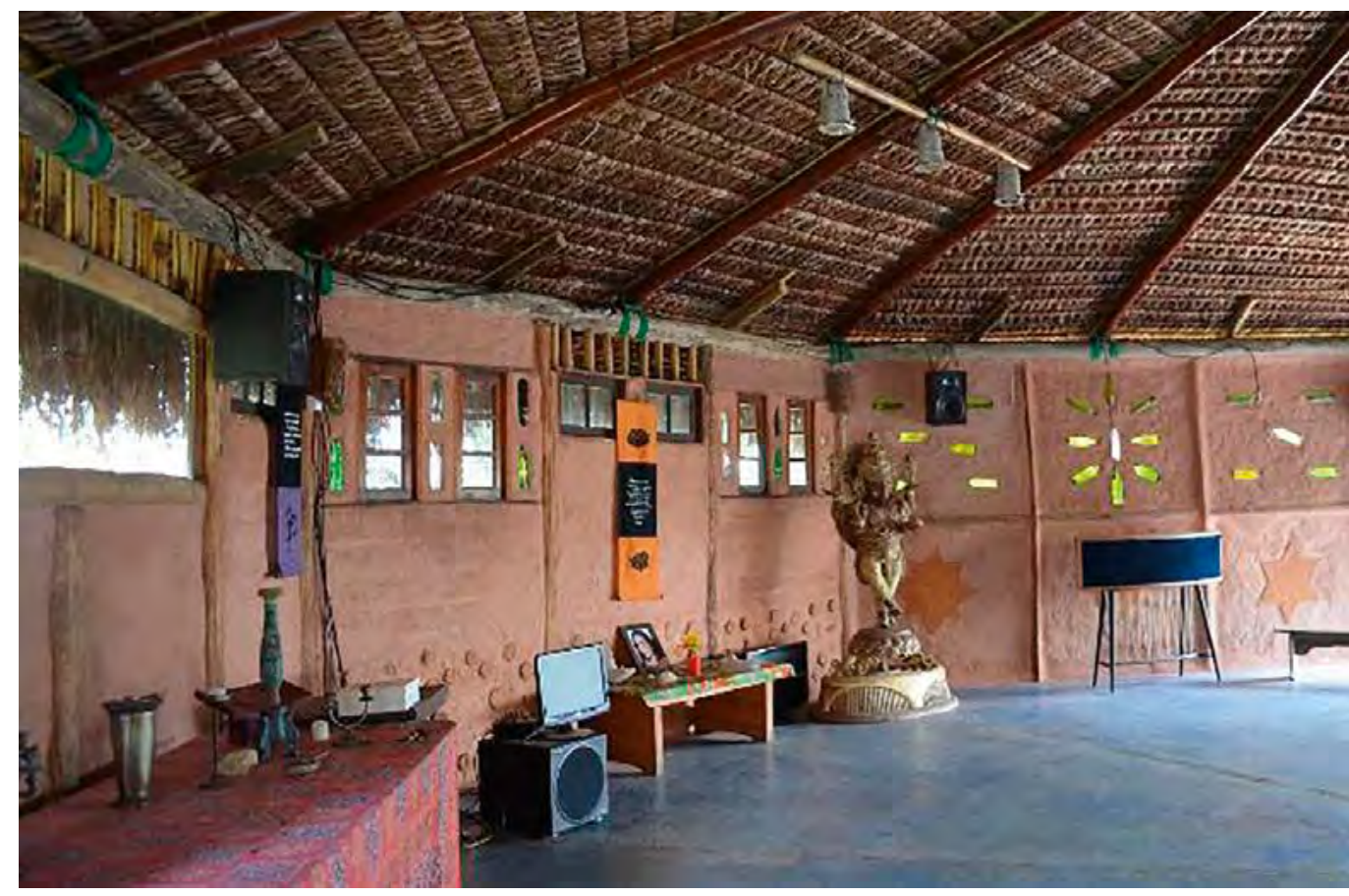

nicas de aplicación de estos materiales naturales se realiza principalmente fuera de la universidad, en cursos que muchas veces se relacionan con la permacultura y la bioconstrucción.

Las dificultades más grandes en su ejercicio profesional están relacionadas con la falta de respaldo técnico por la ausencia de normas e investigaciones confiables sobre aspectos específicos, y escasez de proveedores y de mano de obra. Esto pone en desventaja el valor técnico de estos materiales frente a otros disponibles en el mercado.

Aun así, en esta sociedad que cada vez procura más caminos hacia la sostenibilidad, existe una demanda de estas construcciones con materiales naturales porque también poseen otros valores espirituales y estéticos para los usuarios. Los profesionales entrevistados desarrollaron estrategias de trabajo que les permiten satisfacer estas demandas mientras las respectivas normas de construcción están en proceso de discusión y aprobación.

El reto está en reforzar la parte técnica que garantiza la calidad de la edificación a los usuarios. Para esto es importante formalizar estos conocimientos con la inclusión de la temática en las mallas curriculares de los cursos universitarios de pregrado y posgrado, fomentar la investigación y el desarrollo de normas técnicas, incentivar el desarrollo de cadenas productivas y educar a la población en general.

Finalmente, para responder a la pregunta sobre cuáles son las percepciones de los profesionales y usuarios sobre la durabilidad de las construcciones con materiales naturales en la ciudad de
(A) Figura 7. Aldea Índigo en Florianópolis

Fuente: elaboración propia, 2017. 
Florianópolis, se concluye que aún existe incertidumbre en el tema, aunque en menor grado en el caso de los constructores y proyectistas que la enfrentan en la práctica por medio de la búsqueda de respuestas dentro del área de la técnica.

Los profesionales consiguen superar la preocupación por la durabilidad siendo cuidadosos con la técnica constructiva, adaptando el proyecto y la vida útil a las necesidades de cada usuario, cuidando la selección de los materiales, y por medio de la educación continua.

Esta investigación es un punto de partida para futuros trabajos en el tema de la durabilidad de los materiales naturales en la construcción porque presenta las problemáticas y dificultades que enfrentan los profesionales que trabajan en el área desde hace algunos años.

\section{Agradecimientos}

A la Coordenação de Aperfeiçoamento de Pessoal de Nível Superior (Capes) (Brasil) y a la Secretaría Nacional de Educación Superior, Ciencia y Tecnología (Senescyt) (Ecuador), por las becas que posibilitan el desarrollo de esta investigación de doctorado.

\section{Referencias}

Associação Brasileira de Normas Técnicas (ABNT) (2013). NBR 15575: Edificações habitacionais: Desempenho - Requisitos gerais. Rio de Janeiro: ABNT.

Bardin, L. (1991). Análise de conteúdo. Rio de Janeiro: Edições 70.

Binational Softwood Lumber Council (BSLC) (2009). Tackle Climate Change - Use Wood Minneapolis: North American forest products industry by the BC Forestry Climate Change Working Group; California Forestry Association and WoodWorks. Recuperado de http:// www.softwoodlumber.org/pdfs/Book_Tackle Climate Change Use Wood eVersion. pdf

Comisión Nacional de Ética en Pesquisa de Brasil (Conep) (2018). Conselho nacional de saúde. Brasília: Ministério da Saúde. Recuperado de http://conselho.saude.gov.br/index. php/conep

Espíndola, L. (2010). Habitação de interesse social em madeira conforme os princípios de coordenação modular e conectividade (Disertación de maestría). Universidade Federal de Santa Catarina.

Gifford, R. (2007). Environmental Psychology: Principles and Practice. Colville: Optimal books.

Gropius, Walter (1962, january). The Architect in Society. Architectural Association Journal, s. d.

Hidalgo-López, O. (2003). Bamboo: The gift of the gods. Bogotá: Oscar Hidalgo.

Holmgren, D. (2013). La esencia de la permacultura. Barcelona: Cambium permacultura. Recuperado de https://holmgren.com. au/downloads/Essence_of_PC_ES.pdf

Huxley, J. (1961). The humanist frame. New York: Harper \& Brothers. Recuperado de https://archive.org/details/humanistframe017703mbp

Instituto Brasileiro de Geografia e Estatística (IBGE) (2010). Censo Demográfico - 2010. Rio de Janeiro: IBGE. Recuperado de https:// cidades.ibge.gov.br/brasil/sc/florianopolis/ panorama
Ivelic, M. (1969). El lenguaje arquitectónico. Revista Aisthesis, 4, 39-49. Recuperado de http://revistaaisthesis.uc.cl/index.php/rait/ article/download/600/555

John, V. y Sato, N. (2006). Durabilidade de componentes da construção. En M. Sattler F. y Pereira (eds.), Coletânea Habitare: Construção e meio ambiente (pp. 20-57). Porto Alegre: Antac. Recuperado de http://www. habitare.org.br/ArquivosConteudo/ct 7 comp.pdf

Karnopp-Patrício, Z. (1995). Proposta de formulário de levantamento de dados de abordagem qualitativa. Florianópolis: Núcleo Transcriar - UFSC.

Karnopp-Patrício, Z. (2005). O processo ético e estético de pesquisar: um movimento qualitativo transformando conhecimentos e a qualidade da vida individual-coletiva. Texto de la matéria Introdução à Pesquisa Sócio-Ambiental del Curso de Especialização em Gestão de Recursos Hídricos/UFSC. Florianópolis: Núcleo de Estudos das Águas.

Karnopp-Patrício, Z., Moraes, M., Campanella, E. y Nakadomari, N. (2016). A pesquisa qualitativa e o ente da arquitetura e urbanismo. Contribuição para estudos e o exercício da profissão. Arquitextos, 16(192). Recuperado de http://www.vitruvius.com. br/revistas/read/arquitextos/16.192/6058

Kuhnen, A. (2011). Percepção ambiental. En S. Cavalcante y G. Elali (orgs.). Temas básicos em Psicologia Ambiental (pp. 250-266). Petrópolis: Editora Vozes.

Malard, M. L. (2004). Forma, arquitetura. Interpretar Arquitetura, 6(1), 1-11. Recuperado de http://www.arq.ufmg.br/eva/docs/ art010.pdf

May, J. (2011). Casas hechas a mano y otros edificios tradicionales: arquitectura popular. Barcelona: Blume.

Minayo, M. C. (2014). O desafio do conhecimento: pesquisa qualitativa em saúde. São Paulo: Hucitec Editora.
Minke, G. (2012). Building with Earth: Design and Technology of a Sustainable Architecture. Basilea: Birkhäuser.

Minusma/Sophie Ravier (2015). Crépissage de la Mosque de Djenné. Mali: Mission de I'ONU au Mali - UN Mission in Mali. [Fotografía] (CC BY-NC-SA 2.0). Recuperado de https://www.flickr.com/photos/minusma/ with/17449180208

Morán, J. (2001). Traditional and Current Uses of Bamboo in Latin America, with emphasis in Colombia and Ecuador. Quito: Centro de Investigaciones Territoriales del Ecuador, Escuela Politécnica Nacional.

Randle, G. (2008). El hombre: sentido de la arquitectura y del urbanismo. Buenos Aires: Nobuko.

Rocha-Tamayo, E. (2011). Construcciones sostenibles: materiales, certificaciones y LCA. Revista Nodo, 6(11), 99-116. Recuperado de http://revistas.uan.edu.co/index.php/ nodo/article/view/151/131.

Scopel, V. (2015). Percepção do ambiente e a influência das decisões arquitetônicas em espaços de trabalho. Revista ArqUrb, 13(1), 153-170. Recuperado de http://www.usjt. br/arq.urb/núnmero-13/9-vanessa-scopel. pdf

Silveira, M. y Rodrigues, A. (2015). Touristic Urbanization in Brazil: A focus on Florianópolis - Santa Catarina.Via@, 7(1), 1-13. Recuperado de https://journals.openedition. org/viatourism/625

Soares, A. (2015). Soluções sustentáveis: construção natural. Pirenópolis: Mais Calango editora.

Soares, S., Souza, D. y Pereira, S. (2006). A avaliação do ciclo de vida no contexto da construção civil. En M. A. Sattler y F. O. Ruttkay (eds), Coletânea Habitare - Construção e Meio Ambiente. Porto Alegre: Programa de Tecnologia de Habitação. Recuperado de http://www.habitare.org.br/arquivosconteudo/ct 7 cap4.pdf 



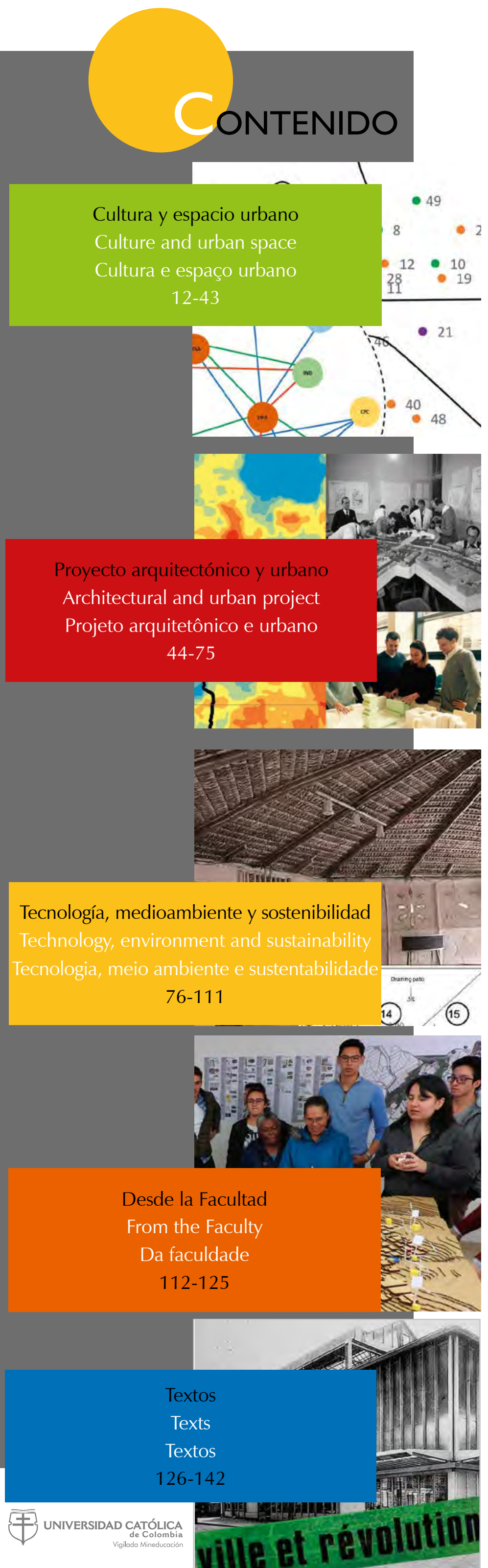

Arquitecturas colectivas y participación como estrategias para la construcción de la ciudad latinoamericana

Myriam Stella Díaz-Osorio

Pág. 3

ES

La caminabilidad en Bogotá: propósitos y condiciones socioespaciales que facilitan y limitan esta experiencia Pablo Páramo

Andrea Burbano

Pág. 12

\section{ES EN}

Planificación comunitaria en barrios socialmente

vulnerables. Identificación de los actores sociales en una comunidad

\footnotetext{
Rafael Alejandro Tavares-Martínez

Jesús Manuel Fitch-Osuna
}

Pág. 22

ES

Desvanecimiento de la frontera como límite. Imaginario del borde como espacio público físico y virtual

Gabriela Eloísa Muñoz-Torres

Susana Gutiérrez-Luna

Pág. 33

Estudiantes latinoamericanos en el Institut

d'Urbanisme de l'Université de Paris (1923-1941)

$$
\begin{aligned}
& \text { Andrés Ávila-Gómez } \quad \text { Pág. } 44 \\
& \text { ES }
\end{aligned}
$$

Apuntes para el repensamiento de la enseñanza de la Arquitectura. La cuestión epistemológica y la necesidad de una razón ampliada
Juan J. Álvarez-Álvarez
Pág. 57

ES

Equipamientos colectivos: "lugares" de producción de capital social
José Mario Mayorga-Henao
Pág. 68
ES
Bucle multidisciplinar para la sustentabilidad urbana

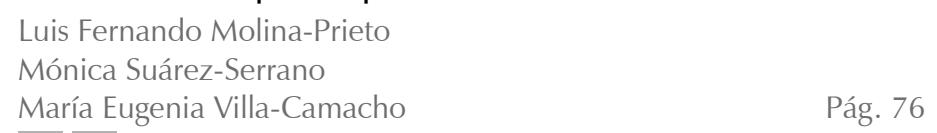

Durabilidad de los materiales naturales de construcción: percepciones de proyectistas, constructores y usuarios en Florianópolis, Brasil

Andrea Salomé Jaramillo-Benavides
Zuleica Maria Patricio-Karnopp
Lisiane Ilha-Librelotto

Pág. 89

\section{ES}

Thermal comfort in buildings for wet processing of coffee

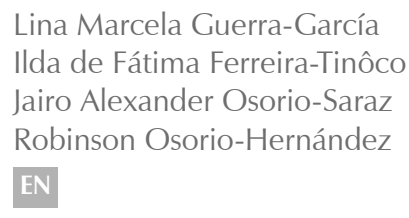

La arquitectura en los barrios: puntos de encuentro entre la academia y el saber popular

Arquitectura, modernidad, modernización

$$
\begin{aligned}
& \text { Jean-Louis Cohen } \\
& \text { Traductores } \\
& \text { Andrés Avila-Gómez } \\
& \text { Diana Carolina Ruiz } \\
& \text { ES } \\
& \text { Revista de Arquitectura (Bogotá) } 126 \\
& \text { E-ISSN: 2357-626X } \\
& \text { ISSN: 1657-0308 }
\end{aligned}
$$


Arquitecturas colectivas y participación como estrategias para la

Arquiteturas coletivas e participação como estratégias para construir a cidad latino-americana

\section{Stella Díaz-Osorio}

La caminabilidad en Bogotá: propósitos y condiciones socioespaciales que facilitan y limitan esta experiencia

The Walkability of Bogotá: purposes and socio-spatial conditions that facilitate and limit this experience

A caminhabilidade em Bogotá: propósitos e condições socioespaciais que facilitam e limitam essa experiência

\section{Andrea Burbano}

Planificación comunitaria en barrios socialmente vulnerables.

Identificación de los actores sociales en una comunidad

Community planning in socially vulnerable neighborhoods.

Identification of social actors in a community

Planejamento comunitário em bairros socialmente vulneráveis.

Identificação dos atores sociais em uma comunidade

Rafael Alejandro Tavares-Martínez

esús Manuel Fitch-Osuna

Desvanecimiento de la frontera como límite. Imaginario del borde como espacio público físico y virtual

$m$

迹

Durabilidad de los materiales naturales de construcción: percepciones de proyectistas, constructores y usuarios en Florianópolis, Brasil

Durability of natural building materials: Perceptions of designers, builders, and users in Florianópolis, Brazil

Durabilidade dos materiais naturais de construção: percepções de projetistas, construtores e usuários em Florianópolis, Brasil

\section{Zuleica Maria Patricio-Karnopp}

Lisiane Ilha-Librelotto

Thermal comfort in buildings for wet processing of coffee

\section{Confort térmico en edificaciones para procesamiento húmedo de café}

Conforto térmico em instalaçōes para processamento úmido de café

\section{Ida de Fátima Ferve-Tartióco}

airo Alexander Osorio-Saraz

Robinson Osorio-Hernandez

La arquitectura en los barrios: puntos de encuentro entre la academia y el saber popular

Architecture in neighborhoods: meeting points between academia and popular knowledge

A arquitetura nos bairros: pontos de encontro entre a academia e o saber popular Hernando Carvajalino-Bayona

\section{Arquitectura, modernidad, modernización}

Architecture, modernity, modernization

Arquitetura, modernidade, modernização
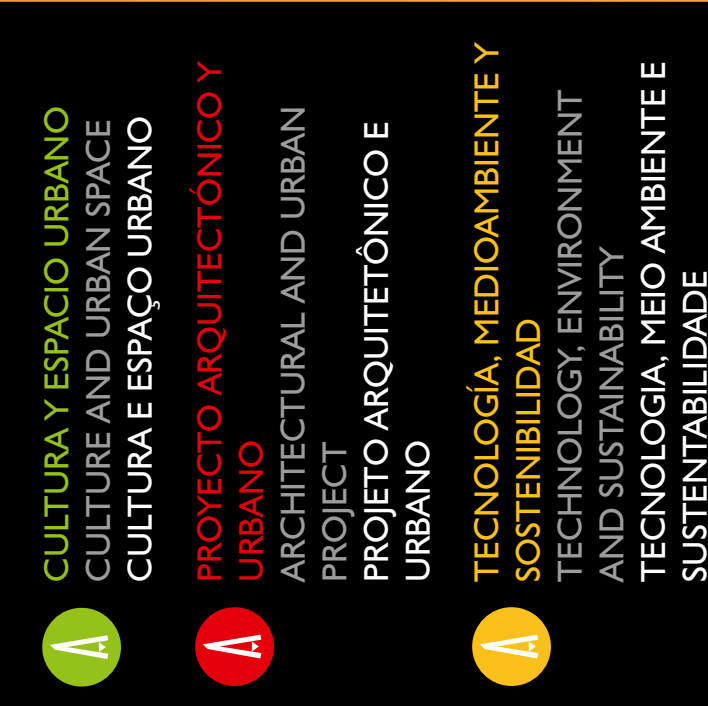

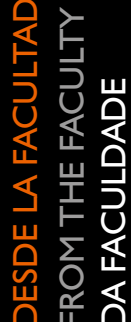

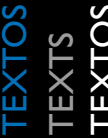
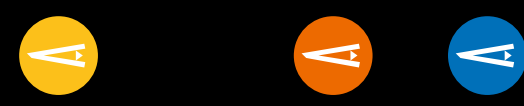

12 Clarivate

ublind

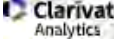

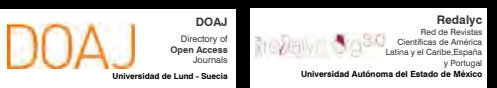

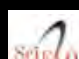

REDIB

EBSCO

cis

latindere

D Dialnet $=$

LatinREV

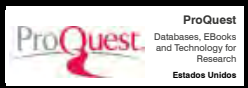

MIคR

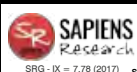

Goos

Google

ARLA

8. https://www.mendeley.com/profiles/revista-de-arquitectura-bogot/
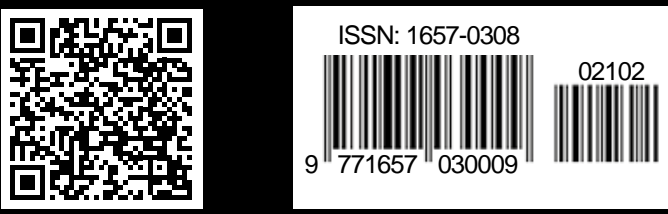